\title{
Spatial Error Modeling and Simulation on Sheet Metal Assembly in Single Station
}

\author{
D.Z. Yu , W.P. Lv, L.H. Zhou , X.H. Xu \\ China Jiliang University \\ Hangzhou, Zhejiang, China
}

\begin{abstract}
Based on analyzing error model of Sheet Metal Assembly, namely SMA, at home and abroad, this paper establishes the propagation model of spatial error of SMA in single station, and founds the rigid error model by differential motion theory and coordinate conversion theory. On condition of satisfying the closed form and closed force, the paper analyzes the assembly deformation errors in positioning and clamping process, connecting process and spring-back process, and sets up the spatial error model of SMA in single station, and then simulates assembly errors by using MATLAB, finally compares them with the results from CATIA-TAA, and there is a good agreement between these results. The model is of significance in the work of assembly error prediction, fixture optimization design, fixture error diagnosis and tolerance synthesis design.
\end{abstract}

Keywords-SMA(Sheet Metal Assembly); Spatial Error; PCCR (Positioning; Clampin; Connecting and Releasing); Closed Form and Closed Force

\section{INTRODUCTION}

Sheet metal subassembly is widely used in automobile, aviation, shipbuilding and instrumentation industries, and the precision of sheet metal subassembly influences its performance, such as the sealing and aerodynamic performance for automobile, the sealing performance and fatigue strength for ship and aircraft [1]-[5]. Nearly two-thirds engineering changes in the automotive and aviation fields are caused by the failure of subassembly [1][2]. Sheet metal part errors, tool errors, clamping deformation errors, connecting deformation errors and spring-back deformation errors are inevitable in the assembly process, and they propagate, accumulate and reduce along the assembly process, and appear to be highly nonlinear and coupling each other, and more importantly the shape and force are also closed in the assembly process [2][13][14]. Traditional superposition theory for rigid body assembly is no longer applicable for sheet metal assembly, therefore more and more scholars pay close attention to the error modeling about sheet metal assembly[4]-[14].

Sheet metal assembly is divided into single station assembly of no relocation and multi-station assembly which is of relocation. Sheet metal assembly in single station should follow PCCR assembly process, including positioning, clamping, connecting and releasing spring-back.[11][13] Hu and Liu established the assembly error model of flexible part in single station in the method of influence coefficient, namely MIC.[7] Camelio and Ceglarek established the assembly error model in single/multi-station by MIC and state space method, and the model was applied to the fixture error diagnosis and error sensitivity analysis [8][9]. Dahlstrom and Liao analyzed and simulated nonlinear contact problem of sheet metal assembly in nonlinear finite element method, namely FEM [10][11]. Stewart analyzed the assembly errors in PCCR assembly process by the piecewise linear elastic method, namely PLEM.[12] Huang established the assembly error model about the open assembly process by linear elastic theory, and deduced in-plane errors and out of plane errors are independent on condition of small deformation, and the fixture and tool errors affecting the assembly deformation can be ignored in open assembly process[14]. Liu and $\mathrm{Hu}$ analyzed three kinds of basic connecting ways which had an effect on the assembly error, and deduced that the overlap-joint way can absorb in-plane error and the butt-joint way can magnify out of plane error [17]. Franciosa modeled and simulated sheet metal assembly error by using SVA-FEA [13]. Huang, Long and Cai simulated the errors on sheet metal assembly in single station by finite element method. The foreign toolkits for error analysis and Simulation, such as 3DCS-FEA, VisVSA-FEA and CATIA -TAA, were encapsulated and difficult to reuse. [13]-[17] Professor Chen guan- long at SJTU constructed the design system in the assembly process based on case reasoning, called BBA, which can generate and optimize the assembly sequence and the joint way [18].

This thesis analyzes the error sources of the assembly process, establishes the rigid error model on sheet metal assembly by differential motion and coordinate transformation, and builds the deformation error model on sheet metal assembly in accordance with the PCCR assembly process on the basis of the analysis of clamping deformation, assembly connecting deformation and spring-back deformation, and finally simulates the errors on sheet metal assembly by MATLAB, and the simulation results are compared with those of CATIA-TAA module.

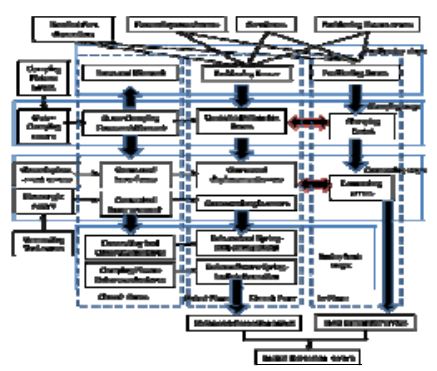

FIGURE I. THE SPATIAL ERROR PROPAGATION KEY POINT ON SHEET METAL PART A AND B 


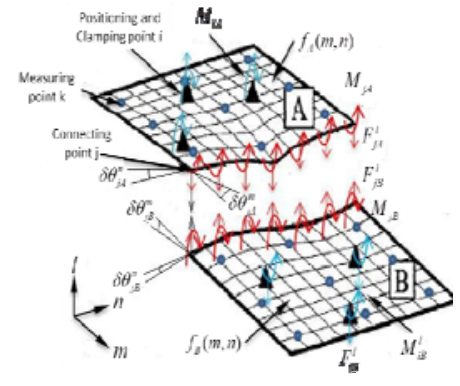

FIGURE II. THE FORCE/MOMENT AND ON ANY DEFORMATION MODEL ON SHEET METAL ASSEMBLY

\section{Station}

Spatial Error Propagation Model on SMA in Single

In order to carry out the research smoothly without loss of generality, the thesis assumes the sheet metal part/subassembly is of in-plane rigidity and out-of-plane flexibility, while out-of-plane deformation belongs to small elastic deformation, which does not affect stiffness matrix of sheet metal part, that is, the stiffness matrix is a constant matrix. The assembly tools, including fixture and connecting tool, are regarded as rigid parts, and these assumptions are fit for $70-80 \%$ sheet metal assembly [1] [2] [13]. Based on the analysis of influence factors and propagation process, the spatial error propagation model on SMA in single station is established in accordance with the PCCR assembly process, as shown in figure 1 . The influence between the in-plane error and the out-of-plane error in the process is represented by double arrows in the figure. The force and moment are always closed in PCCR assembly process because the out of plane form is closed. Because of in-plane rigidity, the rigid error sources include positioning tool error, clamping fixture error and the connecting tool error, on the other hand, the out-of-plane deformation errors exist in the clamping process, connecting process and spring-back process.

\section{Spatial ERRor ANALYZING AND Modeling IN Single STATION}

\section{A. Rigid Spatial Error Modeling on SMA}

In the assembly process, the in-plane errors and out-of-plane errors influence each other, and the assembly errors in each process have affected each other. The in-plane errors are mainly determined by rigid errors, while out-of-plane errors are determined by rigid errors and deformation errors, so the rigid errors of the key point * on the assembly part $\mathrm{J}$ should be denoted as spatial errors, according to the frontal error expression, that is:

${ }^{\mathrm{R}} \delta_{* J}=\left[{ }^{R} \delta_{* J}^{x},{ }^{R} \delta_{* J}^{y},{ }^{R} \delta_{* J}^{z},{ }^{R} \delta \theta_{* J}^{x},{ }^{R} \delta \theta_{* J}^{y},{ }^{R} \delta \theta_{* J}^{z}\right]_{6^{*} \times 1}^{T}=\left(M_{* J_{p_{1}} p_{6}}\right)_{6 \times 6}\left(Q_{* J_{p_{1}} p_{6}}\right)_{6 \times 7}\left(\Delta_{J p_{1} p_{6}}\right)_{7 \times 1}$

In the formula, $\Delta_{p_{1} p_{6}}$ can be denoted as $\left[\delta_{J p l p 1}^{x} \delta_{J p l p 1}^{y} \delta_{J p l p 2}^{x} \delta_{J p l p 2}^{y} \delta_{J p l b 1}^{z} \delta_{J p l b 2}^{z} \delta_{J p l b 3}^{z}\right]^{T}$, which is the errors of the fixture positioning sheet metal part $\mathrm{J}$ with 3-2-1 positioning scheme, and plp1 and plp2 are in-plane four-direction and two-direction positioning pins respectively, plb1, plb2 and

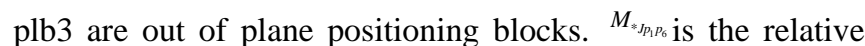
position matrix between the key point * and the four-direction positioning pin plp1, $Q_{* J_{p_{1}} p_{6}}$ is the error influence coefficient of the fixture, $M$ and $Q$ can refer the literature[14].

\section{B. Deformation Error Analyzing and Modeling on SMA in Single Station}

\section{1)Deformation Error Analyzing and Modeling in Clamping} Process

In all part J, external forces on positioning and clamping point i should satisfy the closed forces, as shown in Figure 2, that is.

$$
\sum F_{i J}^{l}=0, \sum M_{i J}^{m}=0, \sum M_{i J}^{n}=0
$$

As is shown in Figure 3, the rigid errors of point $\mathrm{i}$ on part $\mathrm{J}$ and the fixture errors jointly determine the clamping force and the clamping deformation error, and also generate the clamping deformation error on any connecting point $\mathrm{j}$ and any measurement point $\mathrm{k}$, expressed as the formula (3)and (4)respectively.

$$
\begin{gathered}
\left\{\begin{array}{c}
F_{i J}^{l} \\
F_{j J}^{l}
\end{array}\right\}=\left[\begin{array}{ll}
K_{i j J}^{l} & K_{i j J}^{l} \\
K_{j i J}^{l} & K_{j j J}^{l}
\end{array}\right]\left\{\begin{array}{c}
{ }^{R} \delta_{i J}^{l}+\delta_{i J}^{l} \\
\delta_{i j J}^{l}
\end{array}\right\} \\
\left\{\begin{array}{c}
F_{i J}^{l} \\
F_{k J}^{l}
\end{array}\right\}=\left[\begin{array}{ll}
K_{i j J}^{l} & K_{i k J}^{l} \\
K_{k j}^{l} & K_{k L J}^{l}
\end{array}\right]\left\{\begin{array}{c}
R \\
\delta_{i J}^{l}+\delta_{i j}^{l} \\
\delta_{i k J}^{l}
\end{array}\right\}
\end{gathered}
$$

In the formula, ${ }^{R} \delta_{i j}^{l}$ stands for the rigid error along the direction 1 on positioning and clamping point i on part $\mathrm{J}, \delta_{i J}^{l}$ stands for the corresponding fixture error along the direction 1 of clamping point $\mathrm{i}$ on part $\mathrm{J}, \delta_{i j J}^{l}$ and $\delta_{i k j}^{l}$ stand for the deformation errors along the direction $\mathrm{l}$ produced on connecting point $\mathrm{j}$ and measurement point $\mathrm{k}$ respectively. $F_{i J}^{l}, F_{j J}^{l}$ and $F_{k J}^{l}$ stand for the corresponding external force respectively, and $F_{k J}^{l}$ is usually zero. The angle deformation errors from the clamping moment can be ignored because the clamping forces are vertical with the surface part.
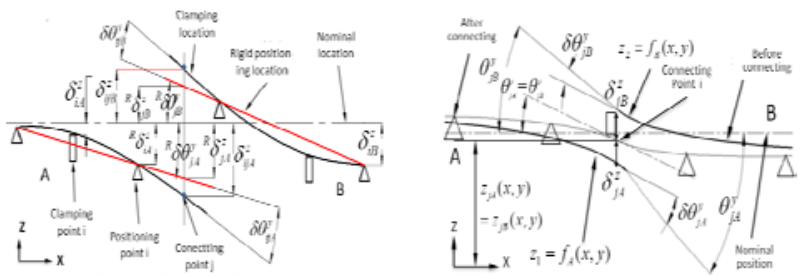

FIGURE III. SCHEMATIC DIAGRAM OF POSITIONING CLAMPING DEFORMATION AND CONNECTING DEFORMATION OF SHEET METAL PART A AND B WHEN OUTER NORMAL LINE L IS Z, AND M IS $\mathrm{X}$

\section{2)Deformation Error Analyzing and Modeling in Connecting Process}

After any sheet metal part $\mathrm{J}$ is connected, the part $\mathrm{J}$ should satisfy the closed force and the close shape on the connecting point $\mathrm{j}$, and the closed forces are shown as Figure 2. The internal and external forces on part $\mathrm{J}$ should keep balance, that 
is.

$$
\begin{aligned}
& \int \sum F_{k J}^{l}+\sum F_{j J}^{l}+\sum F_{j j}^{l}=0 \\
& \sum M_{k J}^{m}+\sum M_{j j}^{m}+\sum M_{i j}^{m}=0 \\
& \sum M_{k J}^{n}+\sum M_{j J}^{n}+\sum M_{i j}^{n}=0(5) \delta_{j A}^{l}=\delta_{j \mathrm{~B}}^{l}, \delta \theta_{j \mathrm{~A}}^{n}=\delta \theta_{j \mathrm{~B}}^{n} \text {, } \\
& \int \delta_{j J}^{l}=z_{j j}^{l}(m, n)-z_{j j}^{0}(m, n), z_{j j}^{l}(m, n)=\left.f_{J}(m, n)\right|_{m=j, n=j} \\
& \delta \theta_{j \mathrm{j}}^{\mathrm{n}}=\theta_{\mathrm{jJ}}^{\mathrm{n}}-\theta_{\mathrm{j}}^{\mathrm{n}}, \theta_{\mathrm{jj}}^{\mathrm{n}}=\left.\frac{\partial f_{J}(m, n)}{\partial m}\right|_{m=j, n=j}
\end{aligned}
$$

In the formula, $F_{j J}^{l},{ }^{M_{j j}^{m}}$ and ${ }^{M_{j J}^{n}}$ stand for the internal force and moments of connecting point j on part J. $F_{i J}^{l}, M_{i j}^{m}$ and $M_{i J}^{n}$ stand for the external force and moments of the positioning and clamping point i on part J. $F_{k J}^{l}, M_{k J}^{m}$ and ${ }^{M_{k J}^{n}}$ stand for the external force and moments of the measuring point $\mathrm{k}$ on part J; and $F_{k J}^{l}, M_{k J}^{m}$ and $M_{k J}^{n}$ are usually zero.

In the assembly process, the part $\mathrm{A}$ and part $\mathrm{B}$ are connected on condition of the closed shape, as is shown in Figure 4. The displacement along the direction 1 and the angle error around $\mathrm{n}$ should satisfy the following formula.

In the formula, $\mathrm{z}_{\mathrm{j} j}^{0}(m, n)$ and $\mathrm{z}_{\mathrm{j} j}(m, n)$ stand for the position function of the connecting point $\mathrm{j}$ on part $\mathrm{J}$ before connecting and after connecting respectively, $\theta_{j j}^{n 0}$ and $\theta_{j j}^{n}$ are the corresponding angle function before connecting and after connecting respectively.

Similarly available the angle error around axis m: At the same time, the out of plane deformation errors and out of plane forces and moments should satisfy the physical equation after connection.

$$
\begin{aligned}
& \delta_{j \mathrm{~A}}^{\prime}=\delta_{j \mathrm{~B}}^{\prime}, \delta \theta_{j \mathrm{~A}}^{m}=\delta \theta_{j \mathrm{~B}}^{m}
\end{aligned}
$$

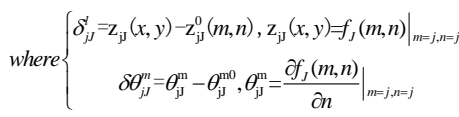

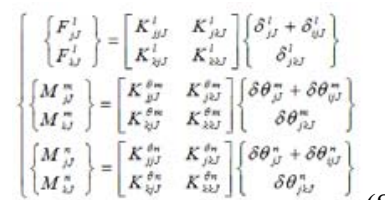

In the formula, $\delta_{j J}^{l}, \delta \theta_{j J}^{m}$ and $\delta \theta_{j J}^{m}$ stand for the connecting tool errors. $\delta_{i j J}^{l}, \delta \theta_{i j J}^{m}$ and $\delta \theta_{i j J}^{n}$ stand for the errors of the connecting point $\mathrm{j}$ after the point $\mathrm{i}$ on part $\mathrm{J}$ is clamped. $\delta_{j k J}^{l}, \delta \theta_{j k J}^{m}$ and $\delta \theta_{j k J}^{n}$ represent the deformation errors of the measuring point $\mathrm{k}$ after the connecting point $\mathrm{j}$ on part $\mathrm{J}$ is closed.

\section{3)Deformation Error Analyzing and Modeling in Spring-Back \\ Process}

In this process, subassembly $\mathrm{AB}$ will generate spring-back deformation errors after releasing the positioning and clamping fixtures and the connecting tools. After releasing the connecting tools, the spring-back deformation error is recorded as $\delta_{k s p r 1}^{l}$, that is the eqn (9).

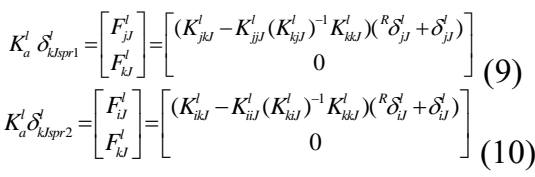

After releasing the positioning and clamping fixture, the spring-back deformation error is recorded as $\delta_{k s p r 2}^{l}$, that is eqn (10).

Moreover, the deformation angle errors generated by ${ }^{m}$ and $M_{j J}^{n}$ are similar to the way above.

4) Deformation Error Modeling About SMA in Single Stations

Based on the analysis of previous section, integrating the positioning and clamping deformation, the connecting deformation and the spring-back deformation errors, that is, the eqn(4), (8), (9) and (10), the deformation error along the direction 1 about SMA is the following:

$$
\begin{aligned}
& { }^{D} \delta_{k J}^{l}=-\left(K_{k j}^{l}\right)^{-1} K_{i i j}^{l}\left({ }^{R} \delta_{i J}^{l}+\delta_{i J}^{l}\right)-K_{k j J}^{l} K_{j j J}^{l}\left({ }^{R} \delta_{j J}^{l}+\left(K_{k j}^{l}\right)^{-1} K_{i i J}^{l}\left({ }^{R} \delta_{i J}^{l}+\delta_{i J}^{l}\right)\right)+\left(K_{\mathrm{a}}^{l}\right)^{-1} \\
& \left(K_{j k J}^{l}-K_{j j J}^{l}\left(K_{j k J}^{l}\right)^{-1} K_{k k J}^{l}\right)\left({ }^{R} \delta_{k J}^{l}+\delta_{j J}^{l}\right)+\left(K_{\mathrm{a}}^{l}\right)^{-1}\left(K_{i k J}^{l}-K_{i j J}^{l}\left(K_{i k J}^{l}\right)^{-1} K_{k k J}^{l}\right)\left({ }^{R} \delta_{k J}^{l}+\delta_{i J}^{l}\right)
\end{aligned}
$$

where, ${ }^{D} \delta_{k J}^{l}$ is the deformation error along the direction 1 on any measurement point $\mathrm{k}$ on part $\mathrm{J},{ }^{R} \delta_{i j}^{l}{ }^{R}{ }^{R}{ }_{j j}^{\prime}$ and ${ }^{R} \delta_{k J}^{l}$ are the rigid errors along direction $\mathrm{l}$ on positioning and clamping point $\mathrm{i}$, connecting point $\mathrm{j}$ and measurement point $\mathrm{k}$ respectively, $\delta_{i j}^{l}$ and $\delta^{l}{ }_{j j}$ stand for the positioning and clamping fixture errors and the connecting tool errors along the direction 1 .

Similarly, the Angle error ${ }^{D} \delta \theta_{k j}^{m}$ is.

$$
\begin{gathered}
{ }^{D} \delta \theta_{k J}^{m}=-\left(K_{k i j}^{\theta m}\right)^{-1} K_{i j J}^{\theta m}\left({ }^{R} \delta_{i J}^{m}+\delta_{i J}^{m}\right)-K_{k j}^{\theta m} K_{j j j}^{\theta m}\left({ }^{R} \delta_{j J}^{\theta m}+\left(K_{k j}^{\theta m}\right)^{-1} K_{i j J}^{\theta m}\left({ }^{R} \delta \theta_{i J}^{m}+\delta \theta_{i J}^{m}\right)\right)+\left(K_{a}^{\theta m}\right)^{-1} \\
\left(K_{j k J}^{\theta m}-K_{j j J}^{\theta m}\left(K_{j k J}^{\theta m}\right)^{-1} K_{k k J}^{\theta m}\right)\left({ }^{R} \delta \theta_{k J}^{m}+\delta \theta_{j J}^{m}\right)+\left(K_{\mathrm{a}}^{\theta m}\right)^{-1}\left(K_{i k J}^{\theta m}-K_{i i J}^{\theta m}\left(K_{i k J}^{\theta m}\right)^{-1} K_{k k J}^{\theta m}\right)\left({ }^{R} \delta \theta_{k J}^{m}+\delta \theta_{i J}^{m}\right)
\end{gathered}
$$

In the formula, each parameter is of the same meaning of the formula (10).

Thus the deformation error of point $\mathrm{k}$ on subassembly $\mathrm{J}$ is.

$$
{ }^{D} \delta_{k J}=\left[\begin{array}{llllll}
{ }^{D} \delta_{k J}^{x} & { }^{D} \delta_{k J}^{y} & { }^{D} \delta_{k J}^{z} & { }^{D} \delta \theta_{k J}^{x} & { }^{D} \delta \theta_{k J}^{y} & { }^{D} \delta \theta_{k J}^{x}
\end{array}\right]^{T}
$$

\section{Spatial Error Model of Sheet Metal Assembly in Single Station}

According to previous analysis, the sheet metal assembly in-plane error is the rigid error, and the out-of-plane error is composed of the rigid error and the deformation error, according to eqn(1), (11), (12) and (13), the assembly error on any measurement point $\mathrm{k}$ on the sheet metal subassembly is.

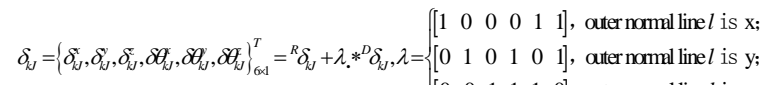

$$
\begin{aligned}
& {\left[\begin{array}{llllll}
0 & 0 & 1 & 1 & 1 & 0
\end{array}\right] \text {, outer nomal linel is z; }(14)}
\end{aligned}
$$

where $\lambda$ is the selection coefficient of the errors. And 
${ }^{R} \delta_{k J}$ stands for the rigid error, and ${ }^{\mathrm{D}} \delta_{k J}$ stands for the deformation error, $*^{*}$ is the operator of the matrix multiplication.

\section{SPATIAL ERROR SIMULATION AND ANALYSIS ON SMA}

The simulation object about Sheet metal assembly in single station is the plat sheet metal $\mathrm{A}$ and $\mathrm{Z}$ type sheet metal $\mathrm{B}$, and the material is aluminum. the specific parameter is shown in Figure 5, PLB1-8 stand for out of plane positioning block respectively, PLP1-4 stand for in-plane positioning pin, and PLP1 and PLP3 are the four-direction positioning pin, while PLP2 and PLP4 are the two-direction positioning pin, the connecting points are PJP1-5 for the flat sheet A and the $\mathrm{Z}$ type sheet $\mathrm{B}$, and PMP1-10 are expressed as the measuring points, the fixture errors of the positioning pin and the positioning block can see the following table 1. According to the analysis process, the assemble deformation errors can be deduced by assembly error model and CATIA-TAA respectively, and is shown in table 2 and table 3 .

TABLE II. CLAMPING, CONNECTING AND SPRING-BACK DEFORMATION ERRORS BY MODEL (MM)

\begin{tabular}{|c|c|c|c|c|c|c|c|c|c|c|}
\hline $\begin{array}{c}\text { Direc } \\
\text { tion } \\
Z\end{array}$ & $\begin{array}{l}\mathbf{P} \\
\mathbf{M} \\
\mathbf{P 1}\end{array}$ & $\begin{array}{l}\text { P } \\
\text { M } \\
\text { P2 }\end{array}$ & $\begin{array}{l}\text { P } \\
\text { M } \\
\text { P3 }\end{array}$ & $\begin{array}{l}\mathbf{P} \\
\mathbf{M} \\
\mathbf{P 4}\end{array}$ & $\begin{array}{l}\mathbf{P} \\
\mathbf{M} \\
\mathbf{P 5}\end{array}$ & $\begin{array}{c}\mathbf{P} \\
\mathbf{M} \\
\mathbf{P 6}\end{array}$ & $\begin{array}{l}\text { P } \\
\text { M } \\
\text { P7 }\end{array}$ & $\begin{array}{l}\text { P } \\
\text { M } \\
\text { P8 }\end{array}$ & $\begin{array}{l}\text { P } \\
\text { M } \\
\text { P9 }\end{array}$ & $\begin{array}{c}\text { PM } \\
\text { P1 } \\
\text { 0 }\end{array}$ \\
\hline $\begin{array}{l}\text { positi } \\
\text { oning } \\
\text { clam } \\
\text { ping }\end{array}$ & $\begin{array}{l}0.0 \\
31\end{array}$ & $\begin{array}{l}0.0 \\
27\end{array}$ & $\begin{array}{l}0.0 \\
22\end{array}$ & $\begin{array}{l}0.0 \\
16\end{array}$ & $\begin{array}{l}0.0 \\
1\end{array}$ & $\begin{array}{l}-0 . \\
03 \\
9\end{array}$ & $\begin{array}{l}-0 . \\
04 \\
2\end{array}$ & $\begin{array}{l}-0 . \\
06 \\
4\end{array}$ & $\begin{array}{l}-0 . \\
08 \\
5\end{array}$ & $\begin{array}{l}-0 . \\
124\end{array}$ \\
\hline $\begin{array}{l}\text { Asse } \\
\text { mbly } \\
\text { conne } \\
\text { cting }\end{array}$ & $\begin{array}{l}0.0 \\
34\end{array}$ & $\begin{array}{l}-0 . \\
01 \\
6\end{array}$ & $\begin{array}{l}-0 . \\
04 \\
5\end{array}$ & $\begin{array}{l}-0 . \\
06\end{array}$ & $\begin{array}{l}-0 . \\
07\end{array}$ & $\begin{array}{l}-0 . \\
08 \\
1\end{array}$ & $\begin{array}{l}-0 . \\
06 \\
5\end{array}$ & $\begin{array}{l}-0 . \\
04 \\
6\end{array}$ & $\begin{array}{l}-0 . \\
04 \\
1\end{array}$ & $\begin{array}{l}-0 . \\
035\end{array}$ \\
\hline $\begin{array}{l}\text { Relea } \\
\text { se } \\
\text { sprin } \\
\text { g-bac } \\
\text { k }\end{array}$ & $\begin{array}{l}0.0 \\
72\end{array}$ & $\begin{array}{l}0.0 \\
61\end{array}$ & $\begin{array}{l}0.0 \\
5\end{array}$ & $\begin{array}{l}0.0 \\
37\end{array}$ & $\begin{array}{l}0.0 \\
02\end{array}$ & $\begin{array}{l}-0 . \\
12 \\
4\end{array}$ & $\begin{array}{l}-0 . \\
13 \\
5\end{array}$ & $\begin{array}{l}-0 . \\
15 \\
4\end{array}$ & $\begin{array}{l}-0 . \\
17 \\
3\end{array}$ & $\begin{array}{l}-0 . \\
185\end{array}$ \\
\hline
\end{tabular}

TABLE III. ClAmping, CONNECTING AND SPRING-BACK DEFORMATION ERRORS BY TAA (MM)

\begin{tabular}{|c|c|c|c|c|c|c|c|c|c|c|}
\hline $\begin{array}{c}\text { Direc } \\
\text { tion } \\
Z\end{array}$ & $\begin{array}{c}\mathbf{P} \\
\mathbf{M} \\
\mathbf{P 1}\end{array}$ & $\begin{array}{l}\mathbf{P} \\
\mathbf{M} \\
\mathbf{P} 2\end{array}$ & $\begin{array}{l}\mathbf{P} \\
\mathbf{M} \\
\mathbf{P 3}\end{array}$ & $\begin{array}{l}\mathbf{P} \\
\mathbf{M} \\
\mathbf{P 4}\end{array}$ & $\begin{array}{l}\mathbf{P} \\
\mathbf{M} \\
\mathbf{P 5}\end{array}$ & $\begin{array}{l}\mathbf{P} \\
\mathbf{M} \\
\mathbf{P 6}\end{array}$ & $\begin{array}{l}\mathbf{P} \\
\mathbf{M} \\
\mathbf{P 7}\end{array}$ & $\begin{array}{l}\mathbf{P} \\
\mathbf{M} \\
\mathbf{P 8}\end{array}$ & $\begin{array}{l}\mathbf{P} \\
\mathbf{M} \\
\mathbf{P 9}\end{array}$ & $\begin{array}{c}\mathbf{P} \\
\mathbf{M} \\
\mathbf{P 1} \\
\mathbf{0}\end{array}$ \\
\hline $\begin{array}{l}\text { positi } \\
\text { oning } \\
\text { clam } \\
\text { ping }\end{array}$ & $\begin{array}{l}0.0 \\
27\end{array}$ & $\begin{array}{l}0.0 \\
40\end{array}$ & $\begin{array}{l}0.0 \\
34\end{array}$ & $\begin{array}{l}0.0 \\
27\end{array}$ & $\begin{array}{l}0.0 \\
19\end{array}$ & $\begin{array}{l}-0 . \\
06 \\
1\end{array}$ & $\begin{array}{l}-0 . \\
08 \\
4\end{array}$ & $\begin{array}{l}-0 . \\
10 \\
6\end{array}$ & $\begin{array}{l}-0 . \\
12 \\
9\end{array}$ & $\begin{array}{l}-0 . \\
154\end{array}$ \\
\hline $\begin{array}{c}\text { Asse } \\
\text { mbly } \\
\text { onnec } \\
\text { ting }\end{array}$ & $\begin{array}{l}0.0 \\
40\end{array}$ & $\begin{array}{l}0.0 \\
23\end{array}$ & $\begin{array}{l}-0 . \\
01 \\
0\end{array}$ & $\begin{array}{l}-0 . \\
03 \\
5\end{array}$ & $\begin{array}{l}-0 . \\
05 \\
3\end{array}$ & $\begin{array}{l}-0 . \\
10 \\
6\end{array}$ & $\begin{array}{l}-0 . \\
09 \\
0\end{array}$ & $\begin{array}{l}-0 . \\
07 \\
1\end{array}$ & $\begin{array}{l}-0 . \\
05 \\
3\end{array}$ & $\begin{array}{l}-0 . \\
032\end{array}$ \\
\hline $\begin{array}{c}\text { Relea } \\
\text { se } \\
\text { sprin } \\
\text { g-bac } \\
\text { k } \\
\end{array}$ & $\begin{array}{l}0.0 \\
76\end{array}$ & $\begin{array}{l}0.0 \\
71\end{array}$ & $\begin{array}{l}0.0 \\
53\end{array}$ & $\begin{array}{l}0.0 \\
47\end{array}$ & $\begin{array}{l}0.0 \\
50\end{array}$ & $\begin{array}{l}-0 . \\
15 \\
7\end{array}$ & $\begin{array}{l}-0 . \\
14 \\
9\end{array}$ & $\begin{array}{l}-0 . \\
14 \\
0\end{array}$ & $\begin{array}{l}-0 . \\
13 \\
1\end{array}$ & $\begin{array}{l}-0 \\
122\end{array}$ \\
\hline
\end{tabular}

Analyzing the $\mathrm{AB}$ assembly process errors, we can obtain: (1) the error change rules on measurement point between assembly error model simulation and CATIA-TAA module simulation are almost similar, and moreover the errors are in the same range $( \pm 0.2)$. (2) the error in the assembly process are affected and controlled by the errors of fixture $( \pm 0.2)$. (3) the connecting error changes are much smaller than CATIA-TAA simulation, mainly because of taking into account the closed shape of the parts in modeling process, and the error changes on each measurement point are much gentler in the connecting process. (4)The measurement error changes of the positioning part A, that is, PMP1-PMP5, are much smaller than the changes of the part $\mathrm{B}$ which is no positioning part after the fixtures and the connecting tools are released.

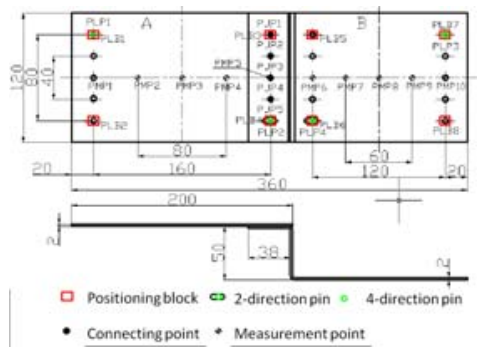

FIGURE IV.SHEET METAL PART A AND B FOR ASSEMBLY SIMULATION

TABLE IV. The Positioning AND CLAMPING FIXTURE ERrors of SHEET METAL PART A AND B (MM)

\begin{tabular}{|c|c|c|c|c|c|c|}
\hline & Out o & $\begin{array}{l}\text { plane } \\
\text { long d }\end{array}$ & $\begin{array}{l}\text { placed } \\
\text { ection }\end{array}$ & rors & $\begin{array}{r}\text { In-pla } \\
\text { er }\end{array}$ & $\begin{array}{l}\mathrm{ex}, y \\
\text { rs }\end{array}$ \\
\hline \multirow[b]{2}{*}{$\begin{array}{c}\text { Part } \\
\text { A }\end{array}$} & PLB1 & PLB2 & PLB3 & PLB4 & PLP1 & PLP2 \\
\hline & 0.2 & 0.15 & 0.2 & 0.15 & $\begin{array}{l}0.12 \\
0.15\end{array}$ & $\begin{array}{l}0.15 \\
0.13\end{array}$ \\
\hline \multirow{2}{*}{$\begin{array}{c}\text { Part } \\
\text { B }\end{array}$} & PLB5 & PLB6 & PLB7 & PLB8 & PLP3 & PLP4 \\
\hline & 0.2 & 0.15 & -0.15 & -0.2 & $\begin{array}{l}-0.05 \\
0.1\end{array}$ & $\begin{array}{l}-0.15 \\
0.15\end{array}$ \\
\hline & 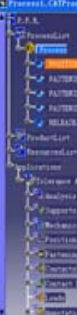 & & 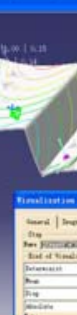 & & 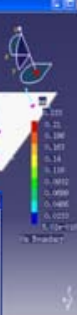 & \\
\hline
\end{tabular}
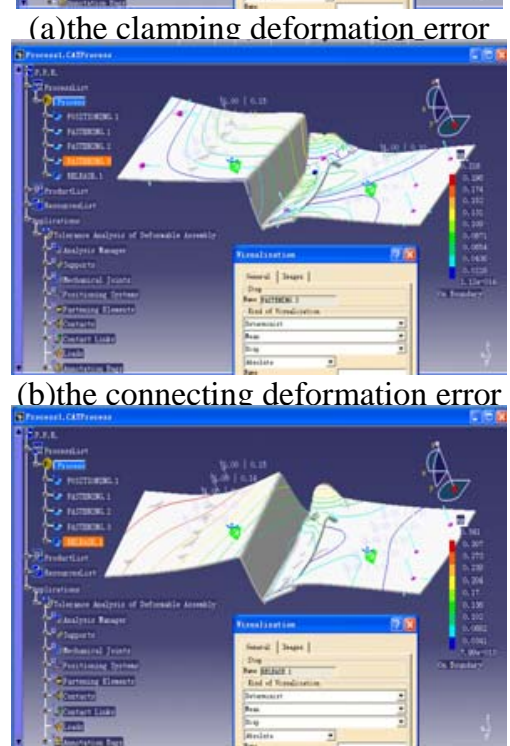

(c) the spring-back deformation error

FIGURE V. THE ASSEMBLY DEFORMATION ERROR 


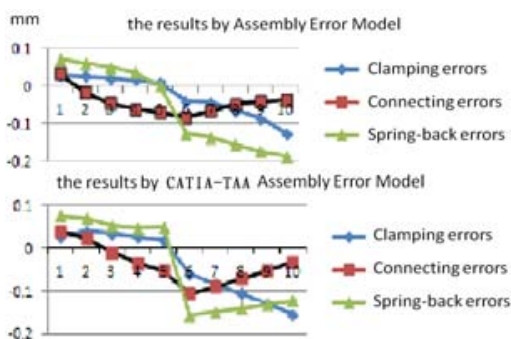

FIGURE VI. THE COMPARISON BETWEEN CATIA-TAA SIMULATION AND MODEL SIMULATION RESULTS

\section{CONCLUSION}

Based on analyzing the rigid positioning errors, the deformation errors, including the clamping errors, the connecting errors and the spring-back errors, are deduced by linear elastic theory in accordance with the PCCR process, and finally built the spatial error model. The main conclusions are summarized as:

(1) According to the PCCR cycle, established the assembly spatial error propagation model on sheet metal assembly in single station.

(2) Based on detailed analysis of deformation errors of the assembly process, including positioning and clamping process, connecting process and releasing spring-back process, the spatial error model of sheet metal assembly was established by the linear elastic theory and finite element method on condition of satisfying the closed force and the closed shape.

(3) Comparing the simulation results of the assembly error model with the CATIA-TAA module simulation results, there is a good agreement between these results, and therefore verified the correctness of the assembly error model.

The model is of significance in the work of assembly error prediction, fixture optimization design, fixture error diagnosis and tolerance synthesis design.

\section{REFERENCE.}

[1] Zhq Lin, Automobile body manufacturing quality control technology, [M],Mechanical Industry Press,2005;

[2] Jj Shi, Stream of Variation Modeling and Analysis for Multiprocess Manufacturing[M], CRC Press,2006;

[3] Zhshn Zhang, Bx He, Jf Shi etc, Research progress of variant multi-step manufacturing process flow [J].Chinese Mechanical Engineering: Vol 21(2),2010;

[4] Xm Lai, Zhq Lin and Gl Chen, The car body assembly deviation control technique [J]. Chinese Mechanical Engineering, Vol $11(11), 1215-1220,2000$

[5] Jh Jin and Jjn Shi, State space modeling of sheet metal assembly for al contro, Journal of Manufacturing Science and Engineering,VOL121,1999.12;

[6] M Hu, Zhq Lin, Xm Lai etc, Simulation and Analysis of Assembly Processes Considering Compliant non-ideal Parts and Tooling Variations [J],International Journal of Machine Tools 41 (2001) 2233-2243;

[7] Charles Liu and Jack Hu, Variation Simulation for Deformable Sheet Metal Assemblies Using Finite Element Methods[J], Journal of Manufacturing Science and Engineering, Vol. 119 ,368-374,August 1997;

[8] S. Jack Hu and Jaime Camelio, Modeling and Control of Compliant Assembly Systems, Annals of the CIRP Vol. 55/1/2006;
[9] Jaime Camelio and Dariusz Ceglarek, Modeling Variation Propagation of Multi-Station Assembly Systems With Compliant Parts[J],Journal of Mechanical Design,Vol125,759-790, 2003.12;

[10] Stefan Dahlstrom and Lars Lindkvist, Contact Modeling in Method of Influence Coefficient for Variation Simulation of Sheet Metal Assemblies, Proceedings of IMECE04,2004;

[11] Xy Liao and G. Gary Wang, Non-linear al variation analysis for sheet metal assemblies by contact modeling, Finite Elements in Analysis and Design 44 (2007) 34-44;

[12] Michael L. Stewart and Kenneth W. Chase, Variation Simulation of Fixtured Assembly Processes for Compliant Structures Using Piecewise-Linear Analysis, ering Congress and Expositi, November 5-11, 2005, Orlando, Florida USA;

[13] Eng. Pasquale Franciosa, Modeling and Simulation of Variational Rigid and Compliant Assembly for Tolerance Analysis[D],University of Naples Federico II, November 2009;

[14] Wzh Huang, Methodologies for Modeling and analysis of stream of variation compliant and rigid assemblies[D], University of Wisconsin-Madison,2004; Yufeng Long, Variation simulation for compliant sheet metal assemblies with applications[D], The University of Michigan,2000;

[15] N Cai and Lh Qiao, al Variation Analysis of Compliant Sheet Metal Assembly[C], 2011 Second International Conference on Digital Manufacturing \& Automation,429-432, 2011;

[16] S. Charles Liu and S. Jack Hu,Sheet Metal Joint Configurations and Their Variation Characteristics, Journal of Manufacturing Science and Engineering, Vol. 120,MAY 1998;

[17] Gl Chen, Jq Zhou and Wn Cai etc, A framework for an automotive body assembly process design system, Computer-Aided Design 38 (2006) 531-538. 